\title{
Phylogenetic congruence between Neotropical primates and plants is driven by frugivory
}

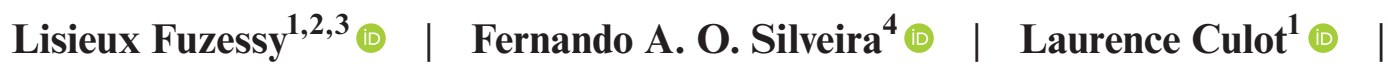

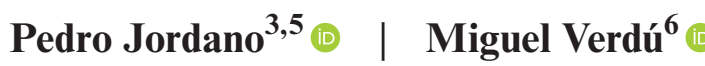

${ }^{1}$ Department of Biodiversity, Universidade Estadual Paulista, UNESP campus Rio Claro, São Paulo, Brazil

${ }^{2} \mathrm{CREAF}$, Centre de Recerca Ecològica i Aplicacions Foresta, Universitat Autònoma de Barcelona, Catalunya, Spain

${ }^{3}$ Estación Biológica de Doñana, EBD-

CSIC, Sevilla, Spain

${ }^{4}$ Department of Genetics, Ecology and Evolution, Universidade Federal de Minas Gerais, Belo Horizonte, Minas Gerais, Brazil

${ }^{5}$ Facultad de Biología, Department Biología Vegetal y Ecología, Universidad de Sevilla, Sevilla, Spain

${ }^{6}$ Centro de Investigaciones sobre Desertificación, CSIC-UV-GV, Moncada, Valencia, Spain

\section{Correspondence}

Lisieux Fuzessy, Department of Biodiversity, Universidade Estadual Paulista, UNESP campus Rio Claro, São Paulo, Brazil

Email:1.fuzessy@creaf.uab.cat

\section{Funding information}

Conselho Nacional de Desenvolvimento Científico e Tecnológico, Grant/Award

Number: 303568/2017-8; Fundação de

Amparo à Pesquisa do Estado de São

Paulo, Grant/Award Number: \#2014/14739-

0, \#2017/07954-0 and \#2018/06634-5;

CYTED Ciencia y Tecnología para el

Desarrollo, Grant/Award Number: Red

418RT0555; Fundação de Amparo à

Pesquisa do Estado de Minas Gerais,

Grant/Award Number: PPM 00382/17

Editor: Timothée Poisot

\begin{abstract}
Seed dispersal benefits plants and frugivores, and potentially drives co-evolution, with consequences to diversification evidenced for, e.g., primates. Evidence for macro-coevolutionary patterns in multi-specific, plant-animal mutualisms is scarce, and the mechanisms driving them remain unexplored. We tested for phylogenetic congruences in primate-plant interactions and showed strong cophylogenetic signals across Neotropical forests, suggesting that both primates and plants share evolutionary history. Phylogenetic congruence between Platyrrhini and Angiosperms was driven by the most generalist primates, modulated by their functional traits, interacting with a wide-range of Angiosperms. Consistently similar eco-evolutionary dynamics seem to be operating irrespective of local assemblages, since co-phylogenetic signal emerged independently across three Neotropical regions. Our analysis supports the idea that macroevolutionary, coevolved patterns among interacting mutualistic partners are driven by super-generalist taxa. Trait convergence among multiple partners within multi-specific assemblages appears as a mechanism favouring these likely coevolved outcomes.
\end{abstract}

\section{K E Y W O R D S}

coevolutionary history, congruent evolution, cophylogenetic signal, macroevolutionary patterns, seed dispersal

\section{INTRODUCTION}

Seed dispersal, a mutualistic interaction resulting from fruit consumption and the deposition of intact seeds is tightly linked with macroevolutionary patterns (Burin et al. 2021) and is a major engine for trait diversification in both plants and frugivores (Gómez \& Verdú 2012; Guimarães et al., 2011; Lengyel et al., 2010; Rojas et al., 2012, but see Scott, 2019). Mutual and reciprocal fitness benefits arise from fruit-frugivore interactions, as fruits are key resources for many vertebrates, and most tropical forest trees rely on fruit-eating vertebrates as seed dispersal vectors (Howe, 2014). Frugivory has evolved independently numerous times along the evolutionary history of vertebrates. This is also true for Neotropical primates (Hawes \& Peres, 2014), a major Order of fruiteating vertebrates (Fleming and Kress, 2013; Lim et al., 2021). Fruit intake is a condition for dispersal potential, 
and all Platyrrhini primates routinely eat fruits (Hawes $\&$ Peres, 2014). The amount of fruit in the diet has significant consequences on the quality components of the seed dispersal effectiveness (Fuzessy et al., 2016, 2017). Yet, the extent to which variation in the degree of frugivory explains a possible shared evolutionary history between primates and Angiosperms remains largely unexplored (but see Gómez and Verdú 2012; Lim et al., 2021).

A persistent knowledge gap preventing a broader understanding of the role of fruit-frugivore interactions in shaping the evolution of primates and plants lies in the methodological challenges in addressing the consequences of seed dispersal to the concurrent diversification of both interacting clades (DeCasien et al 2017, Scott, 2019). Seed dispersal is a mutualistic interaction characterised by low degree of specialisation (Donatti et al., 2011; Stiles \& Rosselli, 1993), and most primates have generalist feeding habits, consuming fruits from a wide range of plant species (Hawes \& Peres, 2014; Heymann \& Fuzessy, 2021; Lim et al., 2021). Thus, the potential of the mutual fitness benefits in promoting plant-primate co-diversification (correlation in speciation events) and/or coevolution (reciprocal evolutionary changes in traits) remains challenging to assess.

Considerable effort has been dedicated to uncover how Primates have diversified, and to what extent behavioural, ecological and morphological traits have contributed to both speciation and extinction rates (Gittleman \& Purvis, 1998; Gómez \& Verdú, 2012; Harcourt et al., 2002; Isaac et al., 2005; Matthews et al., 2011; Nunn et al., 2004). Primates are socially and ecologically complex organisms (Dunbar 2013; Lefebvre et al., 2004; Tran, 2014), but unequivocal evidence supporting the role of frugivory and seed dispersal in primate diversification remains scarce. The capacity to efficiently detect, consume fruits and disperse seeds is linked to larger geographical range sizes, higher diversification rates (Gómez \& Verdú, 2012; Valenta et al., 2018) and cognitive complexity (DeCasien et al. 2017). However, among many traits, activity pattern, but not frugivory, was the only parameter correlated with primate diversification, with higher diversification rates observed in diurnal primates compared to nocturnal species (Scott, 2019). Considering that a diurnal habit is tightly related to primate colour vision, the emerging pattern may also reflect the strict relationship between foraging behaviour and the capacity to visually detect fruits (Kawamura, 2016). For example, the evolution of the trichromatic colour vision by most anthropoid primates has been linked to the efficient detection and selection of food, particularly ripe fruits among leaves in dappled light (Smith et al., 2003).

The evolutionary consequences of seed dispersal also remain unclear from the plant perspective. The intimate relation with certain groups of vertebrates is hypothesised to promote the evolution of dispersal syndromes, i.e. the non-random association of plant traits with specific disperser groups (Gautier-Hion et al., 1985). For instance, many studies attempted to distinguish birddispersed from primate-dispersed fruits based on fruit features such as colour, size and seed traits (GautierHion et al., 1985; Janson, 1983; Lomáscolo et al., 2008; Voigt et al., 2004), but the specificity of such syndromes remains contentious (Valenta et al., 2018).

Theoretical studies on mutualistic networks suggest that the establishment of a link between two partners occurs when an interaction evolves successfully (Burin et al. 2021), and more species can be connected by evolutionary trait convergence (Guimarães et al., 2011). Although we are still unable to draw strong evidence of the potential of seed dispersal in promoting reciprocal selective responses between closely linked primates and plants (but see Guimarães et al., 2017), recent ecophylogenetic tools allow us to assess both the shared evolutionary histories and the contribution of a particular clade to the coevolutionary dynamics (BlascoCosta et al. 2021; Hutchinson et al., 2017). In particular, eco-phylogenetic analyses allow the detection of a nonrandom shared pattern or signal in the evolutionary trajectories of interacting species (e.g. frugivores and plants, hosts and parasites).

Estimation of the cophylogenetic signals (CS) in fruitprimate interactions allows quantifying the degree at which the topology and chronology of the phylogenies of interacting clades are congruent, and whether interaction between evolutionarily coupled taxa still occurs. Thus, CS underscores more precise inferences on how ecological interactions shape diversification patterns (Aizen et al., 2016; Balbuena et al., 2013; Hutchinson et al., 2017).

Here we tested for a phylogenetic congruence in primates and plants at both continental and regional scales in the Neotropics, the most biodiverse region of the planet (Raven et al., 2020). Under a strong CS, we expected a low overlap in fruit consumption among primates and other fruit-eating vertebrates, since strong associations may involve strong reciprocal and exclusive selection pressures (prediction I). We further assessed whether the magnitude of CS is driven by (1) the number of interactions performed (i.e. the generalism degree), (2) primate functional traits related to fruit consumption, such as feeding guilds and frugivory degree (the proportion of fruits in the diet relative to other items, Hawes \& Peres, 2014), and (3) dispersal-relevant fruit and seed traits known to shape seed dispersal abilities (fruit length and seed diameter). The contribution of seed dispersal to primate diversification was mostly mediated by the broadening of mutualists' geographic ranges (Gómez \& Verdú, 2012). Therefore, we expect that primate species with a broad range of interaction partners belong to lineages with higher diversification and will contribute the most to the CS; plant species performing the lowest number of 
interactions as a consequence of morphological constraints related to dispersal (large seeds and fruits) will contribute the most to the CS, since those species tend to be exclusively or primarily dispersed by primates (prediction II) (Jordano, 1995; Valenta et al., 2018). As a consequence, seed and fruit sizes are expected to be plant traits defining the CS strength (prediction III) (Jordano, 1995; Valenta et al., 2018). Finally, CS is particularly expected to arise in the most frugivorous lineages of primates, whereas less frugivorous feeding guilds and the lowest frugivory degrees will contribute less to define the past history shared among Neotropical primates and Angiosperms (prediction IV).

\section{MATERIALS AND METHODS}

\section{Database}

We performed a comprehensive literature search on plant species potentially dispersed by Neotropical primates, using both Web of Science and Google Scholar. Search details and the complete list of studies are available in Supplementary Material S1.

To evaluate the overlap in fruit consumption between primates with other vertebrates, based on the list for primates, we searched for other vertebrates also interacting with the fruits. We obtained records of frugivore-plant interactions whenever seeds were recorded to have been either swallowed and potentially defecated intact, or spit and/ or spat out intact by animals away from the parent tree. We obtained data for birds, bats, small mammals and ungulates (Supplementary Material S2).

\section{Phylogenetic reconstruction}

We used ultrametric phylogenies and reconstructed both plant and primate phylogeny at the species-level. Detailed information on phylogenetic reconstruction methods is provided in Supplementary Material S3.

\section{Cophylogenetic signal (CS)}

To test for a CS between Angiosperms and primates, we implemented a Procrustean Approach to Cophylogeny (PACo; Balbuena et al., 2013). Under high CS values, diversification patterns of associated organisms over evolutionary time tend to be dependent, and congruences (i.e. topological similarity) between the phylogenies of interacting clades are expected to occur. The PACo approach addresses such phylogenetic congruence by optimising the topological fit of two phylogenies using interaction graphs of a given matrix (detailed explanation of the procedure is available in Suplementary Material S4).
Congruence expresses the extent to which each node in a given phylogenetic tree corresponds to a position in the phylogenetic tree of the interacting clade. A perfect congruence can be interpreted as a strong cospeciation evidence, which may or may not result from coevolutionary mechanisms. In nature, in addition to cospeciation, other types of evolutionary events can act concurrently, so such a perfect fit is rarely observed. Thus, the cophylogenetic signal is estimated by the squared residual distance, $r$, between two corresponding points in the phylogenetic trees of two interacting clades. PACo thus returns a quantification of the global fit of the topologies of the phylogenies based on observed interactions as the sum of squared residual distances $\left(R=\sum r^{2}\right)$ between phylogenetic-interaction graphs (Balbuena et al., 2013). As in any regression analysis, the smaller the residual distances (Procrustean residuals), the better the fit of the two phylogenies to each other and the more support for a hypothesis of CS as reflected by the extant interactions (Hutchinson et al., 2017).

High CS illustrates a strong congruency of the phylogenies of the two partner groups. Procrustean residuals measure the variation in the topological fit that is not explained by the co-phylogenetic structure of the interaction matrix, so that interactions with small Procrustean residuals contribute the most to CS, whereas those deviating more from the expectation derived from the shared phylogenetic history contribute the less to CS. CS was considered to be significant when it was smaller than $95 \%$ of the values obtained from 1000 randomisations of the aggregated interaction dataset.

To ensure that the continental-level cophylogenetic pattern was not due to distinct geographical subsets of primate plants coexisting in different regions, we split our dataset into the major Neotropical forests (Morrone 2014): Atlantic, Amazon and Mesoamerican forests. We then filtered our dataset and obtained, for each region, specific phylogenies of plants and primates, and their respective seed dispersal interactions. We then measured the CS and tested for its significance following the same statistical approach as for the continent-wide assessment.

\section{The influence of interaction degree and functional traits on CS}

We firstly characterised each primate and plant species by its interaction degree, i.e. the total number of interactions performed in our dataset. To assess how the interaction degree of plants and primates affect the magnitude of the CS, we fitted two Generalised Linear Mixed Models (GLMMs) using the 'ImerTest' package (Kuznetsova et al., 2017), one for plants and one for primates. Abundant species tend to be generalists, so to account for the variation in geographic distribution area among primate species, we used primate geographic range as a proxy of their density, given the lack 
of abundance data for each specific site. This approach is supported by strong associations between species distribution ranges and population sizes (Chiarello \& Melo 2001; Estrada et al. 2017). Data on primate distribution range (in $\mathrm{km}^{2}$ ) were extracted from IUCN maps (IUCN 2021). In each model, we then used Procrustean residuals calculated by the PACo function as the response variable, the primate distribution area as a random effect, and the interaction degree of plants and primates as predictor variables.

Then, we obtained data on primate (body size, degree of frugivory and dietary guild) and plant functional traits (fruit length and seed diameter) from the literature. As primate functional traits, we included variables recognised to influence the potential of fruit consumption. We calculated primate frugivory degree as the percentage of the diet that corresponds to fruit with pulp, excluding seed predatory interactions (data from Hawes \& Peres, 2014), and we divided primates into five dietary guilds based on the percentage of food items in the diet: frugivores, folivores, insectivores, omnivores and seed predators. For plant traits, we included variables recognised to define consumption by frugivores. Details on classification and data collection are provided in Supplementary Material S5. To test whether functional traits of primates and plants influence the magnitude of the CS, we fitted a GLMM and included the Procrustean residuals calculated by the PACo function as the response variable and functional traits as predictor variables. We tested the model for multicollinearity of the variables by using the variance inflation factor (VIF). Multicollinearity occurs when two or more predictors are correlated and provide redundant information about the response. VIF values for body size were found to be high (VIF $=10.83$, tolerance $=0.09$ ), which were also correlated with model intercept (0.9). Further, we obtained AIC values for both models, with and without body size, and found that the model without body size had the lowest value. Facing the likely confounding effects of body size added to the collinearity produced, and the AIC values, we removed this variable from our model (see Supplementary Material S6).

To account for the possible influence of sample size of interactions and primate geographic range, we also used the total time spent in the field and primate distribution area as random variables in the GLMM. Information on the total time spent in the field was extracted from the studies from which we obtained data on interactions (Supplementary Material S6).

The final GLMM model included then Procrustean residuals as a response variable, primate species, plant species, sampling effort and primate distribution area as random effects, and functional traits (frugivory degree and dietary guilds for primates; fruit length and seed diameter for plants) as fixed effects.

\section{RESULTS}

We gathered information on 1632 interactions between 39 primate species, and 964 plant species distributed in 312 genera and 98 families across Neotropical rainforests. Primates were the exclusive seed dispersers of 627 (65\%) species (in 233 genera) (Figure 1). Birds overlapped 147 plant species with primates (in 80 genera), bats 48 (in 32 genera), ungulates 17 (in 16 genera) and small mammals 9 (in nine genera). Finally, 112 plant species (in 68 genera) were found to be dispersed by primates and more than one vertebrate group. The most primate-exclusively dispersed family was Sapotaceae (70 species, or $5.5 \%$ of the total 1273 species), followed by Menispermaceae (22 species, or $5 \%$ of the 440 species) and Moraceae (44 species, or $3.7 \%$ of the 1180 species) (Figure $\mathrm{S} 7$ ).

\section{Continent-wide patterns}

We detected a coupled evolutionary history among primates and plants based on seed dispersal, as evidenced by a strong and significant cophylogenetic signal $\left(\mathrm{R}_{\text {Continental }}=0.98, p<0.001\right)$. The residual contribution to the overall magnitude of the signal varied among interacting species. Specialisation or generalisation of each primate species (quantified by the number of interaction partners) predicted the CS of their interactions: the most interacting primates (those presenting highest degrees) had the shortest residual distances, thus contributing more to the CS $(t=-2.39, p=0.02)$. In turn, the number of interactions performed by plants had no influence on the CS $(t=1.79, p=0.07$, Figure S8).

The folivores (Alouatta) and the major frugivorous primates (Ateles, Lagothrix and Brachyteles) contributed more to the strength of the CS, followed by the omnivores (Cebus and Sapajus) and frugivore-insectivores (Leontopithecus, Leontocebus and Saguinus). On the other hand, mostly seed predators (Cacajao, Chiropotes and Callicebus species) showed the largest Procrustean residual values, with the smallest contribution to the signal (Figure 2, Tables S9 and S10a).

Primate functional traits (degree of frugivory: $\mathrm{F}_{\text {Continental }}=3.18, p=0.04$; feeding guild: $\left.\mathrm{F}_{\text {Continental }}=574.56, p<0.001\right)$, but not plant traits (fruit length: $\mathrm{F}_{\text {Continental }}=2.53, p=0.11$; seed diameter: $\mathrm{F}_{\text {Continental }}=0.89, p=0.35$ ), determined the magnitude of the influence of the interaction on the overall CS.

\section{Regional-scale assessment}

The continental pattern was consistent when brokendown at the regional scale. We found a strong and significant CS on primate-fruit interactions in the Atlantic forest $\left(\mathrm{R}_{\text {Atlantic }}=0.98, p<0.001\right)$, Amazon 


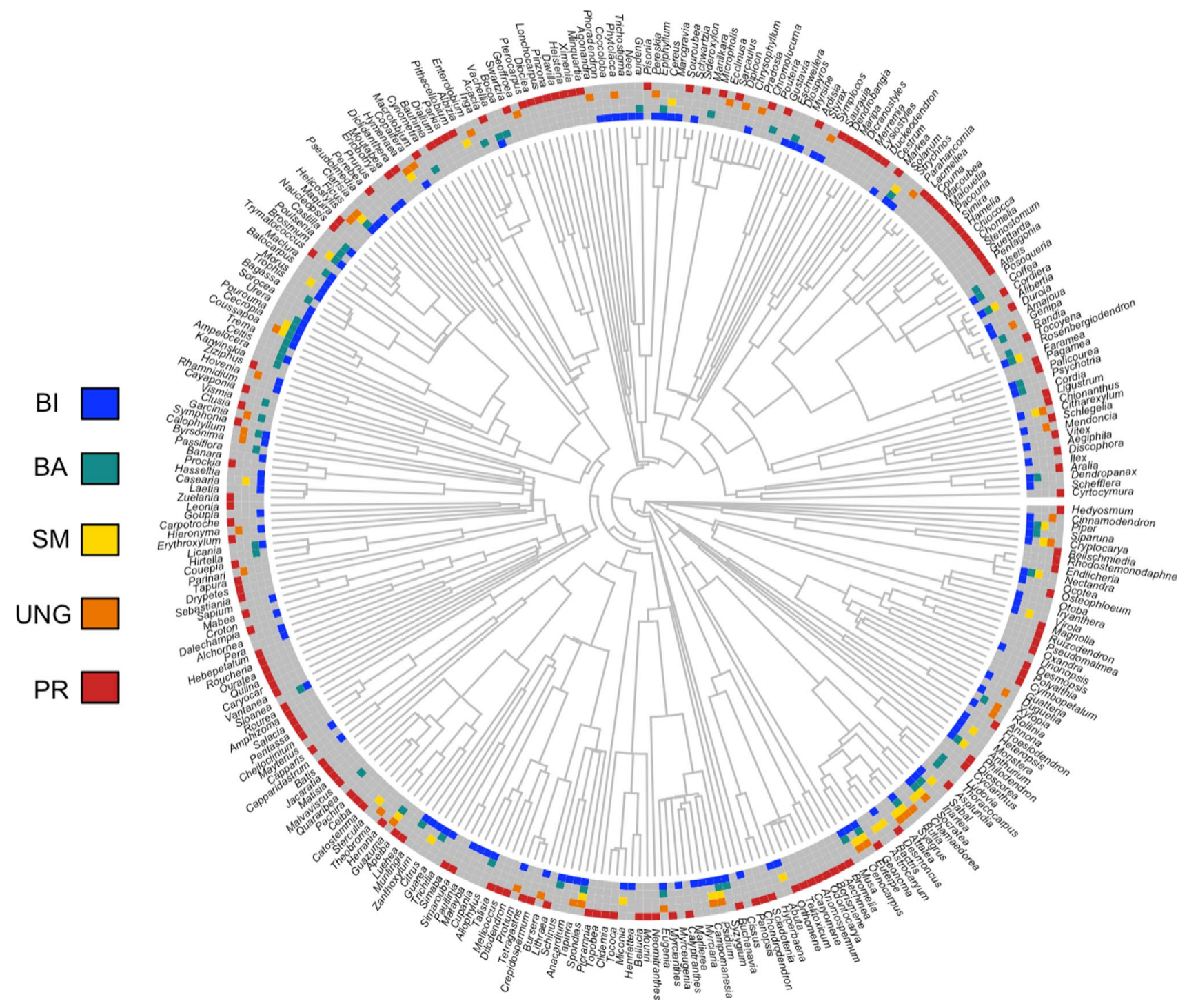

F I G U R E 1 Genus-level megatree of Neotropical angiosperms dispersed by primates and other vertebrate frugivores. BI, bird, BA, bat, SM, small mammal, UNG, ungulate, PR, exclusively primate

$\left(\mathrm{R}_{\text {Amazon }}=0.98, p<0.001\right)$ and Mesoamerica (specieslevel: $\mathrm{R}_{\text {Mesoamerican }}=0.98, p<0.001$ ).

Feeding guild was the most important variable accounting for variation in the magnitude of the CS, regardless of biogeographic region $\left(\mathrm{F}_{\text {Atlantic }}=373.7, p<0.001\right.$; $\mathrm{F}_{\text {Amazon }}=323.7, p<0.001 ; \mathrm{F}_{\text {Mesoamerican }}=95.7, p=0.01$, Tables S10). The contribution by each primate feeding guild in the Atlantic forest followed the continental pattern, where folivores contributed the most to the CS, followed by major frugivores, omnivores, insectivores and predators. In the Amazon, the major frugivores had the greatest contribution, whereas omnivores had the greatest contribution in Mesoamerican rainforests (Figure 3).

The only effect detected for plant functional traits was observed in the Amazon, where fruit length determined the contribution of the interaction to the CS $\left(\mathrm{F}_{\text {Amazon }}=9.94, p=0.002\right)$. We observed no other effect of plant traits (see Tables S10).

\section{DISCUSSION}

Understanding the eco-evolutionary dynamics of species interactions remains challenging due to intrinsic complexities involved in mutualisms, especially in speciesrich communities (Hall et al., 2020). Further complexities arise from the multi-specific, mega-diversified nature of most mutualisms among free-living species, but also from difficulties to infer process from the simple cophylogenetic patterns (Poisot, 2015). Seed dispersal has been hypothesised to drive coevolution between plants and frugivores, shaping the present-day patterns of interactions and the evolution of fruit traits (Eriksson, 2016; Guimarães et al., 2011, 2017; Lengyel et al., 2010; Rojas et al., 2012), but empirical evidence remains elusive both for pattern and process. Using an unprecedented database of fruit-frugivore interactions, we show a significant cophylogenetic signal (CS), which reveals that 


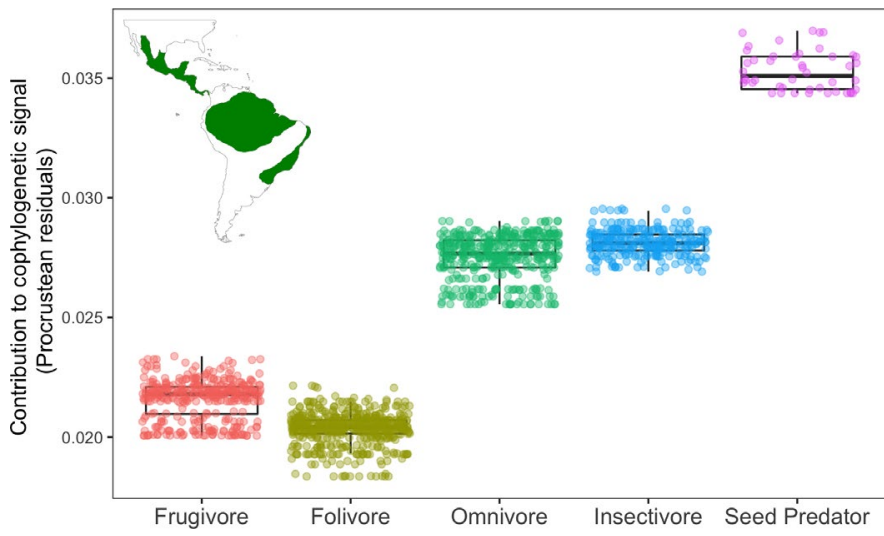

F I G U R E 2 Contribution to the overall co-phylogenetic signal (CS) by primate feeding guild at continental scale (Neotropic). Lower residual values represent higher contributions to the CS. Boxplots show the median, upper and lower quartiles, and minimum and maximum observed values. Scattered dots represent individual Procrustean residual values for each primate species

phylogenies of Neotropical primates and Angiosperms are strongly coupled, and provide support for the longstanding claims that interactions between Angiosperms and primates are shaped by coevolution (Eriksson, 2016; Sussman, 1991, 1995).

CS emerged independently in three tropical rainforests (Mesoamerica, Amazonia and Atlantic Forest), and the consistency between the continental and regional scales evidences spatial replication of the process and supports the idea of similar eco-evolutionary dynamics operating irrespective of species composition in regional meta-communities. The observed CS was mainly driven by generalist primates dispersing a diverse assemblage of angiosperms, partially in agreement with our prediction II. On the other hand, contraring our prediction III, plant functional traits were not important to define CS either at continental or at local scales, except for fruit size in the Amazon. As for primates function, CS emerged primarily in primate lineages with the highest degrees of fruit consumption, whereas less frugivorous feeding guilds and/or the lowest frugivory degrees were less important to define the past history shared among Neotropical primates and Angiosperms regardless of spatial scales, as expected by our prediction IV.

Recent estimates suggest primate origins from 55.8 to 50.3 Mya, in the early Eocene (O'Leary et al., 2013), consistent with the rise and dominance of modern tropical rainforests lineages (Carvalho et al. 2021; Sussman, 2017). Primate diversification entailed changes in locomotion, reproductive biology, skull morphology, dentition and feeding niches, which likely arose as a coevolutionary response to fruiting plants (Sussman et al., 2013). In New World primates, the divergence times in the modern Platyrrhini are estimated to be 20.1 Mya, during the Oligocene-Miocene boundary (Schrago, 2007). This was nearly the time of diversification of many extant lineages of fleshy-fruited Angiosperms. Even though many families seem to have conserved fruit traits ever since the Eocene (Eriksson et al., 2000), drupes and berries, the most consumed fleshy-fruits by primates, have evolved much more recently. For instance, Bolmgren and Eriksson (2005) found that almost half of fleshy-fruited clades are younger than $40 \mathrm{Mya}$, and many examples in dominant and keystone plant resources in Arecaceae, Rubiaceae, Solanaceae and in the Myrtales experienced a remarkable increase in diversification between 40 and 18 Mya (Berger et al. 2016; Eriksson, 2016). This timescale overlap in diversification of both Neotropical primates and fleshy-fruiting plants is consistent with the idea that seed dispersal played a role in their coupled evolutionary history.

Seed dispersal clearly drove the congruence in phylogenies, as evidenced from strong effects of the primate frugivory-related traits. Chronological evidence supports the origin of primate frugivory at the end of the first stage of Angiosperm diversification (Eriksson, 2016). As expected, the cophylogenetic relation among plants and primates was shaped mainly by the most frugivorous species, although specific plant traits were not pivotal in driving such a signal. Primarily frugivores and folivores belong to the Atelidae family, the largest among Neotropical primates. Atelids are the most important and legitimate seed dispersers in neotropics (Fuzessy et al., 2016) and contributed the most to the cophylogenetic signal. On the other hand, seed predators, belonging to the Pitheciidae family, had the least contribution. It suggests that similar mechanisms might be operating for dietary guilds within a same family. Seed predators are absent in Mesoamerican forests (Estrada et al. 2006), where frugivore-insectivores were found to contribute the least, wheras omnivores followed by frugivores and folivores were those with the highest contribution to the CS. Among-guild differences in contribution may be a consequence of the relative importance of guild species diversity in each region, added to their conservation status, and therefore the number of interactions performed. For instance, in the Atlantic Forest, the only frugivores are the species of Brachyteles, both threatened by extinction. On the 

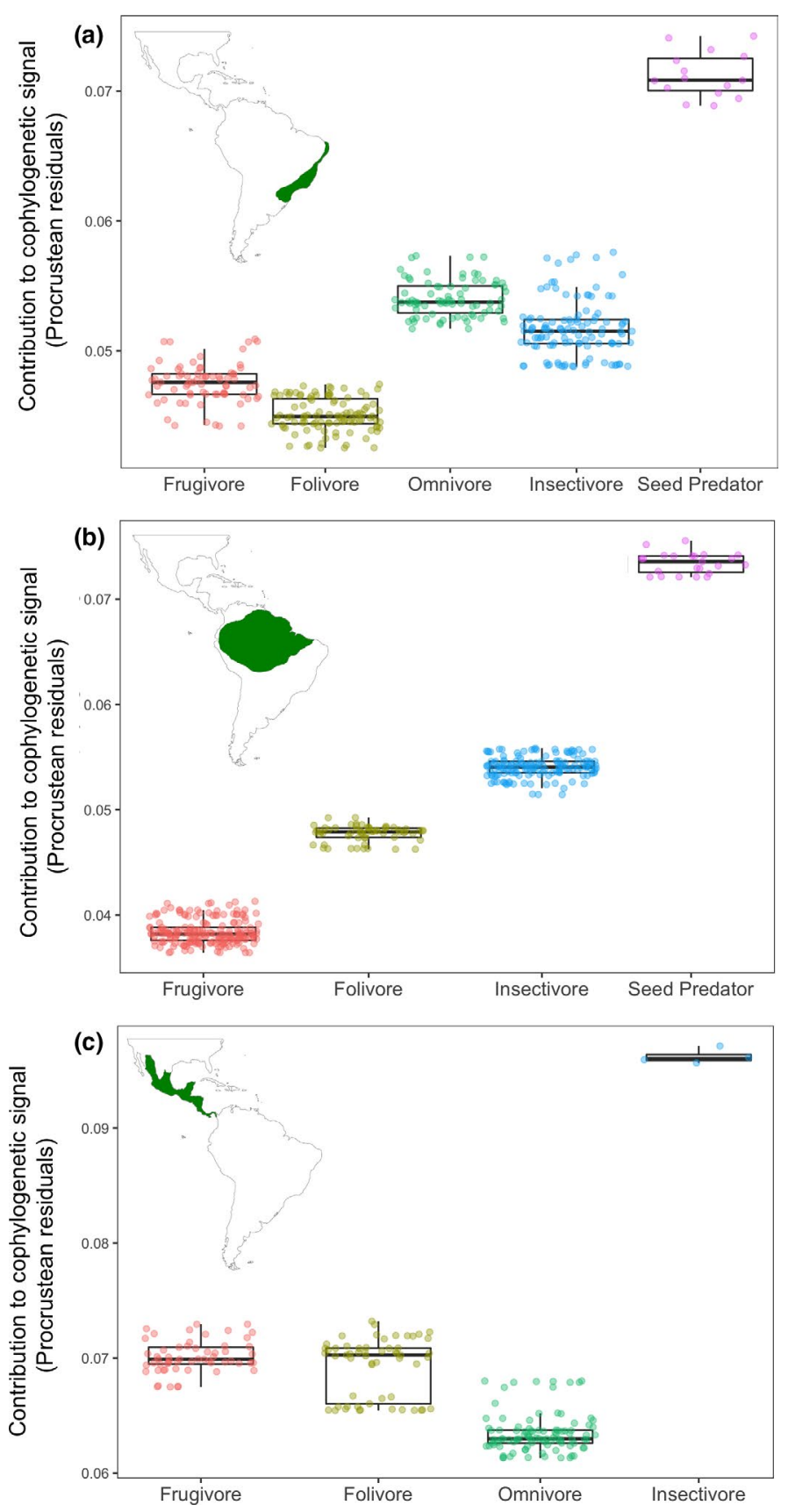

F I G U R E 3 Contribution to the overall co-phylogenetic signal (CS) by primate feeding guild at regional scale (a-Atlantic forest, bAmazon forest, and c-Mesoamerican forest) considering plant phylogeny at species level. Lower residual values represent higher contributions to the CS. Boxplots show the median, upper and lower quartiles, and minimum and maximum observed values. Scattered dots represent individual Procrustean residual values for each primate species

other hand, in the Amazon, Ateles and the Lagothrix play the most important role as frugivores and are much better represented.

Recent studies on the visual adaptations of primates support intrinsic relationships between primate diversification and the capacity to detect plant resources (Valenta et al., 2018, Onstein et al., 2020, but see Heymann \& Fuzessy, 2021). The evolution of modern primates, therefore, may be directly related to improved means of efficiently exploiting fleshy fruits (Sussman, 2017), although, in some cases, evidence is limited to particular clades and recent times (e.g. Onstein et al., 2020). Our analysis reveals tree-wide contributions to the CS, although some clades (e.g. Atelidae) had larger contributions. These findings, together with the evidence of an early frugivorous habit over primate diversification (Sussman et al., 2013), support the prominent phylogenetic congruence in Neotropical primate-fruit interactions driven by primate frugivore-related, functional traits. It also provides clues that diversification is an ongoing process, given the large contribution from recent Plathyrrini clades. 
Reconstructing Angiosperm evolutionary history based on fruit traits as a response to selective pressures generated by interacting primates is still challenging. In this case, the phenotypic responses may be more strongly subjected to phylogenetic constraints, i.e. reflect inherited ancestral characteristics rather than traits adapted to an ecological niche (Jordano, 1995; Valenta \& Nevo, 2020). Our results suggest that diaspore size, key morphological constraint to the establishment of mutualistic interactions (Dehling et al., 2014), was not an important driver of the CS. Most studies evaluating plant adaptive responses to mutualisms with primates based on current empirical data have found weak evidences of phylogenetic signals (Valenta et al., 2016, Valenta et al., 2018 - fruit colour; Nevo et al., 2018, Nevo et al., 2020-fruit scent; Valenta et al., 2016-size, mass and hardness), a likely consequence of the low specificity found in extant interactions.

Frugivorous birds and mammals are the major seed dispersers in the tropics (Fleming and Kress 2013). Considering the primate-centered basis of our dataset, and despite the low overlap in fruit consumption among primates and other fruit-eating vertebrates, complying with our prediction I, our results reflect the trend of plants to share multiple dispersers. This is not only true for recent times, so it is important to consider that, throughout evolutionary history, primates were not the only interacting taxa with the radiating fruiting plants.

At the time of Angiosperm radiation, the diversification of the earliest modern-looking primates in parallel with that of other mammals and fruit-eating birds, propelled the beginning of a shared evolutionary relationship (Sussman, 2017). It helps us to explain how such low specificity prevents detection of strong phylogenetic patterns. However, the CS arose even in a supergeneralist system where other frugivorous groups may be also shaping plant diversification. We also observed a dissimilarity in terms of the number of interactions performed by each plant and primate species explaining the influence on the CS: primates dispersing the greater diversity of plants (i.e. generalists) contributed the most to CS strength, while no effect of plant degree was detected.

Besides fruits, Platyrrhini primates also include leaves, flowers, seeds, nuts, nectar, and animal prey as feeding resources (Hawes \& Peres, 2014; Lim et al., 2021). Distinct amounts of each item vary across taxa (Hawes \& Peres, 2014; Lim et al., 2021), thus less frugivorous primates and other coexisting frugivorous clades may act together favouring a process known as diffuse coevolution (Erikson 2016). It is unlikely that frugivores and plants share a very tight coevolutionary history (Valenta \& Nevo, 2020), such as those observed in host-parasite interactions (Brooks, 1988; Gandon \& Michalakis, 2002), or plant-pollinator interactions (Herrera, 2019). Instead, spatio-temporal asymmetries, disruptions in relationships between patterns, and shifts between periods of coevolution among coexisting clades should lead to reciprocal adaptive changes, ultimately resulting in a weak process (Erikson 2016), as suggested by our results. Primate evolution seems to have somehow "tracked" plant radiations, resulting in a coevolutionary history with asymmetric influences.

The multi-specific nature of the process delineating the CS does not mean that primates and plants have not coevolved or that coevolution has necessarily been the primary force fueling diversification (see, e.g. Althoff et al., 2014; Poisot, 2015). Instead, it seems to occur in a much more complex framework, including both direct and indirect effects underlined by three non-exclusive main processes (Guimarães et al., 2011, 2017). First, selection regimes imposed by generalised multiple-partner interactions, such as seed dispersal, are the outcome of a complex interplay among selection pressures operating through multiple pathways, leading to slow, but continuous, coevolution. Coevolution repeatedly reshapes selection regimes and species traits by speeding up the overall diversification rate in interacting clades. Second, coevolution results in higher trait complementarity among interacting partners (reduced mismatch and increased trait convergence), and the level of integration may provide a mechanism for the emergence of community-level trait patterns. Finally, convergence tends to be higher in the presence of super-generalists, here represented by the most frugivorous primates, which interact with a wide-range of plant species and thus establish the magnitude of the observed CS. Our results indicate a strong non-random pattern in the diversification of primarily primate-dispersed neotropical plants and their primate disperser partners, reinforced by the replicated consistency found in three major neotropical biomes. Although the processes involved in such highlevel macroevolutionary patterns remain obscure, our approach highlights replicated consistency over large biogeographic extents and evidences the strong potential of highly diversified mutualisms among free-living species in macroevolution.

\section{ACKNOWLEDGEMENTS}

LFF and LC received funding from FAPESP, \#2017/07954-0, \#2018/06634-5, \#2014/14739-0; MV and PJ from CYTED (Red 418RT0555); FAOS thanks support from $\mathrm{CNPq}$ and FAPEMIG. We thank E. W. Heymann and three anonymous reviewers for comments provided and J. A. Balbuena for statistical advice.

\section{AUTHORSHIP}

All authors conceived the ideas; LFF and MV designed the methodology and analysed the data; LFF and FAOS led data collection; LFF led the writing of the manuscript. All authors contributed critically to the drafts and gave final approval for publication. 


\section{PEER REVIEW}

The peer review history for this article is available at https://publons.com/publon/10.1111/ele.13918.

\section{DATA AVAILABILITY STATEMENT}

All published data sources are referenced in the manuscript (main text and/or supplementary material). At the time of publication, raw data will be available at https:// github.com/LFuzessy (https://doi.org/10.5281/zenodo. 5578594).

\section{ORCID}

Lisieux Fuzessy (10 https://orcid. org/0000-0001-9599-9782

Fernando A. O. Silveira (1) https://orcid. org/0000-0001-9700-7521

Laurence Culot (1) https://orcid.org/0000-0002-3353-0134 Pedro Jordano (D) https://orcid.org/0000-0003-2142-9116 Miguel Verdú (10 https://orcid.org/0000-0002-9778-7692

\section{REFERENCES}

Aizen, M.A., Gleiser, G., Sabatino, M., Gilarranz, L.J., Bascompte, J. \& Verdu, M. (2016) The phylogenetic structure of plantpollinator networks increases with habitat size and isolation. Ecology Letters, 19, 29-36.

Althoff, D.M., Segraves, K.A. \& Johnson, M.T.J. (2014) Testing for coevolutionary diversification: linking pattern with process. Trends in Ecology \& Evolution, 29, 82-89.

Balbuena, A.J., Miguez-Lozano, R. \& Blasco-Costa, I. (2013) PACo: a novel procrustes application to cophylogenetic analysis. PlosOne, 8, e61048.

Berger, B.A., Kriebel, R., Spalink, D. \& Sytsma, K.J. (2016) Divergence times, historical biogeography, and shifts in speciation rates of Myrtales. Molecular Phylogenetics and Evolution, 95, 116-136. Available from: https://doi.org/10.1016/j.ympev.2015.10.001

Blasco-Costa, I., Hayward, A., Poulin, R. \& Balbuena, J.A. (2021) Next-generation cophylogeny: unravelling eco-evolutionary processes. Trends in Ecology \& Evolution, 36(10), 907-918. Available from: https://doi.org/10.1016/j.tree.2021.06.006

Bolmgren, K. \& Eriksson, O. (2005) Fleshy fruits: origins, niche shifts, and diversification. Oikos, 109, 255-272.

Brooks, D.R. (1988) Macroevolutionary comparisosns of host and parasite phylogenies. Annual Review of Ecology, Evolution, and Systematics, 19, 235-259.

Burín, G., Guimarães, P.R. \& Quental, T.B. (2021) Macroevolutionary stability predicts interaction patterns of species in seed dispersal networks. Science, 372, 733-737.

Carvalho, M.R., Jaramillo, C., de la Parra, F., Caballero-Rodríguez, D., Herrera, F., Wing, S. et al. (2021) Extinction at the endCretaceous and the origin of modern Neotropical rainforests. Science, 372(6537), 63-68. Available from: https://doi.org/10.1126/ science.abf 1969

Chiarello, A.G. \& de Melo, F.R. (2001) Primate population densities and sizes in Atlantic forest Remnants of Northern Espírito Santo, Brazil International Journal of Primatology, 22(3), 379396. Available from: https://doi.org/10.1023/a:1010751527749

DeCasein, A.R., Williams, S.A. \& Higham, J.P. (2017) Primate brain size is predicted by diet but not sociality. Nature Ecology \& Evolution, 1, 0112.

Dehling, D.M., Töpfer, T., Schaefer, H.M., Jordano, P., Böhning-Gaese, K. \& Schleuning, M. (2014) Functional relationships beyond species richness patterns: trait matching in plant-bird mutualisms across scales. Global Ecology and Biogeography, 23(10), 1085-1093. Available from: https://doi.org/10.1111/geb.12193.
Donatti, C.I., Guimarães, P.R., Galetti, M., Pizo, M.A., Marquitti, F.M.D. \& Dirzo, R. (2011) Analysis of a hyper-diverse seed dispersal network: modularity and underlying mechanisms. Ecology Letters, 14(8), 773-781. Available from: https://doi. org/10.1111/j.1461-0248.2011.01639.x

Dunbar, R.I.M. (2013) Primate social systems. Ithaca, NY: Cornell University Press. vii, pp. 1-373.

Eriksson, O. (2016) Evolution of angiosperm seed disperser mutualisms: the timing of origins and their consequences for coevolutionary interactions between angiosperms and frugivores. Biological Reviews, 91, 168-186.

Eriksson, O., Friis, E.M. \& Löfgren, P. (2000) Seed size, fruit size, and dispersal systems in angiosperms from the Early Cretaceous to the Late Tertiary. American Naturalist, 156, 47-58.

Estrada, A., Garber, P.A., Pavelka, M.S.M. \& Luecke, L. (2006). Overview of the mesoamerican primate fauna, primate studies, and conservation concerns. In: Estrada, A., Garber, P.A., Pavelka, M.S.M. \& Luecke, L. (Eds.) New perspectives in the study of Mesoamerican primate. developments in primatology: progress and prospects. Boston, MA: Springer, pp. 1-22.

Estrada, A., Garber, P.A., Rylands, A.B., Roos, C., FernandezDuque, E., Di Fiore, A. et al. (2017) Impending extinction crisis of the world's primates: why primates matter. Science Advances, 3(1). Available from: https://doi.org/10.1126/sciadv.1600946

Fleming, T.H. \& Kress, W.J. (2013) The ornaments of life. Coevolution and conservation in the tropics. Chicago: University of Chicago Press.

Fuzessy, L.F., Cornelissen, T.G., Janson, C.H. \& Silveira, F.A.O. (2016) How do primates affect seed germination? A meta-analysis of gut passage effects on neotropical plants. Oikos, 125, 1069-1080.

Fuzessy, L.F., Janson, C.H. \& Silveira, F.A.O. (2017) How far do Neotropical primates disperse seeds? American Journal of Primatology, 79, e22659.

Gandon, S. \& Michalakis, Y. (2002) Local adaptation, evolutionary potential and host-parasite coevolution: interactions between migration, mutation, population size and generation time. Journal of Evolutionary Biology, 15(3), 451-462. Available from: https://doi.org/10.1046/j.1420-9101.2002.00402.x

Gautier-Hion, A., Duplantier, J.-M., Quris, R., Feer, F., Sourd, C., Decoux, J.-P. et al. (1985) Fruit characters as a basis of fruit choice and seed dispersal in a tropical forest vertebrate community. Oecologia, 65, 324-337.

Gittleman, J. \& Purvis, A. (1998) Body size and species-richness in carnivores and primates. Proceedings of the Royal Society of London. Series B: Biological Sciences, 265, 113-119.

Gómez, J.M. \& Verdú, M. (2012) Mutualism with plants drives primate diversification. Systematic Biology, 61, 567-577.

Guimarães, P.R., Jordano, P. \& Thompson, J.N. (2011) Evolution and coevolution in mutualistic networks. Ecology Letters, 14, 877-885.

Guimarães, P.R., Pires, M.M., Jordano, P., Bascompte, J. \& Thompson, J.N. (2017) Indirect effects drive coevolution in mutualistic networks. Nature, 550, 511-514.

Hall, A.R., Ashby, B., Bascompte, J. \& King, K.C. (2020) Measuring coevolutionary dynamics in species-rich communities. Trends in Ecology \& Evolution, 35, 539-550.

Harcourt A. H., Coppeto S. A., Parks S. A. (2002) Rarity, specialization and extinction in primates. Journal of Biogeography, 29(4), 445. -456. Available from: https://doi. org/10.1046/j.1365-2699.2002.00685.x

Hawes, J.E. \& Peres, C.A. (2014) Ecological correlates of trophic status and frugivory in neotropical primates. Oikos, 123(3), 365-377. Available from: https://doi.org/10.1111/j.1600-0706.2013.00745.x

Herrera, C.M. (2020) Flower traits, habitat, and phylogeny as predictors of pollinator service: a plant community perspective. Ecological Monographs, 90(2). Available from: https://doi. org/10.1002/ecm.1402

Heymann, E.W. \& Fuzessy, L.F. (2021). Are palms a good model to explain primate colour vision diversification? A comment on 
Onstein et al. 2020. Proceedings of the Royal Society B, 288, 20201423.

Howe, H.F. (2014) Diversity storage: implications for tropical conservation and restoration. Global Ecology and Conservation, 2, 349-358. Available from: https://doi.org/10.1016/j.gecco.2014. 10.004

Hutchinson, M.C., Cagua, E.F. \& Stouffer, D.B. (2017) Cophylogenetic signal is detectable in pollination interactions across ecological scales. Ecology, 98(10), 2640-2652. Available from: https://doi org/10.1002/ecy.1955

Isaac, N.J., Jones, K.E., Gittleman, J.L. \& Purvis, A. (2005) Correlates of species richness in mammals: body size, life history, and ecology. American Naturalist, 165(5), 600-607.

IUCN (2021). The IUCN Red List of Threatened Species. Version 2021-2. Available from: https://www.iucnredlist.org [Accessed 13th April 2021].

Janson, C.H. (1983) Adaptationof fruitmorphologyto dis- persal agentsin a neotropicalforest. Science, 219, 187-189.

Jordano, P. (1995) Angiosperm fleshy fruits and seed dispersers: a comparative analysis of adaptation and constraints in plantanimal interactions. The American Naturalist, 145(2), 163-191. Available from: https://doi.org/10.1086/285735

Kawamura, S. (2016) Color vision diversity and significance in primates inferred from genetic and field studies. Genes Genomics, 38, 779-791.

Kuznetsova, A., Brockhoff, P.B. \& Christensen, R.H.B. (2017) lmerTest Package: tests in linear mixed effects models. Journal of Statistical Software, 82(13). Available from: https://doi. org/10.18637/jss.v082.i13

Lefebvre, L.S., Reader, M. \& Sol, D. (2004) Brains, innovations and evolution in birds and primates. Brain, Behavior and Evolution, $63,233-246$

Lengyel, S., Gove, A.D., Latimer, A.M., Majer, J.D. \& Dunn, R.R. (2010) Convergent evolution of seed dispersal by ants, and phylogeny and biogeography in flowering plants: a global survey. PEPEES, 12, 43-55.

Lim, J.Y., Wasserman, M.D., Veen, J., Després-Einspenner, M.-L. \& Kissling, D. (2021) Ecological and evolutionary significance of primates' most consumed plant families. Proc Royal Soc B, 288 , 20210737.

Lomáscolo, S.B., Speranza, P. \& Kimball, R.T. (2008) Correlated evolution of fig size and color supports the dispersal syndromes hypothesis. Oecologia, 156, 783-796.

Matthews, L.J., Arnold, C., Machanda, Z. \& Nunn, C.H. (2011) Primate extinction risk and historical patterns of speciation and extinction in relation to body mass. Proceedings of the Royal Society B: Biological Sciences, 278, 1256-1263.

Morrone, J.J. (2014) Biogeographical regionalisation of the Neotropical region. Zootaxa, 3782(1), 1. Available from: https:// doi.org/10.11646/zootaxa.3782.1.1

Nevo, O., Razafimandimby, D., Jeffrey, J.A.J., Schulz, S. \& Ayasse, M. (2018) Fruit scent as an evolved signal to primate seed dispersal. Science Advances, 4, eaat4871.

Nevo, O., Valenta, K., Kleiner, A., Razafimandimby, D., Jeffrey, J.A.J., Chapman, C.A. et al. (2020) The evolution of fruit scent: phylogenetic and developmental constraints. BMC Evolutionary Biology, 20, 138.

Nunn, C.L., Altizer, S., Sechrest, W., Jones, K.E., Barton, R.A. \& Gittleman, J.L. (2004) Parasites and the evolutionary diversification of Primate clades. American Naturalist, 164, S90-S103.

O'Leary, M.A., Bloch, J.I., Flynn, J.J., Gaudin, T.J., Giallombardo, A., Giannini, N.P. et al. (2013) The placental mammal ancestor and the post-K-Pg radiation of placentals. Science, 339, 662-667.

Onstein, R.E., Vink, D.N., Veen, J., Barratt, C.D., Flantua, S.G.A., Wich, S.A. et al. (2020) Palm fruit colours are linked to the broad-scale distribution and diversification of primate colour vision systems. Proceedings of the Royal Society B: Biological Sciences, 287, 20192731
Poisot, T. (2015). When is co-phylogeny evidence of coevolution? In: Morand, S., Krasnov, B.R. \& Littlewood, D.T.J. (Eds.) Parasite diversity and diversification: evolutionary ecology meets phylogenetics. Cambridge, MA: Cambridge University Press, pp. 420-433.

Raven, P.H., Gereau, R.E., Phillipson, P.B., Chatelain, C., Jenkins, C.N. \& Ulloa Ulloa, C. (2020) The distribution of biodiversity richness in the tropics. Science Advances, 6(37), eabc6228.

Rojas, D., Vale, Á., Ferrero, V. \& Navarro, L. (2012) The role of frugivory in the diversification of bats in the Neotropics. Journal of Biogeography, 39(11), 1948-1960.

Schrago, C.G. (2007) On the time scale of new world primate diversification. American Journal of Physical Anthropology, 132(3), $344-354$.

Scott, J.E. (2019) Macroevolutionary effects on primate trophic evolution and their implications for reconstructing primate origins. Journal of Human Evolution, 133, 1-12.

Smith, A.C., Buchanan-Smith, H.M., Surridge, A.K., Osorio, D. \& Mundy, N.I. (2003) The effect of colour vision status on the detection and selection of fruits by tamarins (Saguinus spp.). Journal of Experimental Biology, 206, 3159-3165.

Stiles, F.G. \& Rosselli, L. (1993) Consumption of fruits of the Melastomataceae by birds: how diffuse is coevolution? Vegetatio, $108,57-73$

Sussman, R.W. (1991) Primate origins and the evolution of angiosperms. American Journal of Primatology, 23(4), 209-223.

Sussman, R.W. (1995) How primates invented the rainforest and vice-versa. In: Alterman, L., Doyle, G.A. \& Izard, M.K. (Eds.) Creatures of the dark. Boston, MA: Springer, pp. 1-10.

Sussman, R.W. (2017) Angiosperm radiation theory. In: Fuentes, A. (Ed.) The international encyclopedia of primatology. West Sussex: John Wiley \& Sons Inc, pp. 1-3.

Sussman R.W., Rasmussen D.T., Raven P.H. (2013) Rethinking primate origins again. American Journal of Primatology, 75(2), 95106. Available from: https://doi.org/10.1002/ajp.22096

Tran, L.A.P. (2014) The role of ecological opportunity in shaping disparate diversification trajectories in a bicontinental primate radiation. Proceedings of the Royal Society B, 281, 20131979.

Valenta, K., Miller, C.N., Monckton, S.K., Melin, A.D., Lehman, S.M., Styler, S.A. et al. (2016) Fruit ripening signals and cues in a Madagascan dry forest: haptic indicators reliably indicate fruit ripeness to dichromatic lemurs. Evolutionary Biology, 43(3), 344 355. Available from: https://doi.org/10.1007/s11692-016-9374-7

Valenta, K. \& Nevo, O. (2020) The dispersal syndrome hypothesis: how animals shaped fruit traits, and how they did not. Functional Ecology, 34, 1158-1169.

Valenta, K., Nevo, O. \& Chapman, C.A. (2018) Primate fruit color: useful concept or alluring myth? International Journal of Primatology, 39(3), 321-337. Available from: https://doi. org/10.1007/s10764-018-0025-y

Voigt, F., Bleher, B., Fietz, J., Ganzhorn, J., Schwab, D. \& BöhningGaese, K. (2004) A comparison of morphological and chemical fruit traits between two sites with different frugivore assemblages. Oecologia, 141, 94-104.

\section{SUPPORTING INFORMATION}

Additional supporting information may be found in the online version of the article at the publisher's website.

How to cite this article: Fuzessy, L., Silveira, F.A.O., Culot, L., Jordano, P. \& Verdú, M. (2021) Phylogenetic congruence between Neotropical primates and plants is driven by frugivory. Ecology Letters, 00, 1-10. https://doi.org/10.1111/ele.13918 